\title{
The Research of Chinese College Student Cadres' Leadership Style Based on the Contingency Theory
}

\author{
Liangtie Dai, Qing Cai \\ School of Management, Jinan University, Guangzhou, China \\ Email:373673703@qq.com
}

Received 7 October 2014; revised 8 November 2014; accepted 5 December 2014

Academic Editor: Charbel J. C. Jabbour, UNESP-Sao Paulo State University, Bauru, Brazil

Copyright (C) 2014 by authors and Scientific Research Publishing Inc.

This work is licensed under the Creative Commons Attribution International License (CC BY).

http://creativecommons.org/licenses/by/4.0/

C) (i) Open Access

\begin{abstract}
This article is written from the view of contingency theory. It analyses the types of Chinese college student cadres' leadership style and the types' connection with gender, organization functions and performance. At the same time, it explores the most suitable style for the college student organization, and hopes to provide some relevant recommendations to higher education's talent cultivation.
\end{abstract}

Keywords

Leadership Style, Human Resource Management, Contingency Theory, Management Psychology

\section{Introduction}

Since 1999, in order to solve the economics and employment issues, China has expanded the numbers of university enrollment. Since then, the number of college students in China has been reached its highest level and talent cultivation problems of colleges and universities were also increasingly received attention. Colleges paid more attention to the quality of education and the ability of applying knowledge.

With these changes, a salient trend is the increasing number of student organizations, such as student union and Youth League Committee. After the intense college entrance examination, many students began to aware of the importance of practice ability, so they chose to join the associations, student unions, Youth League Committee, etc. Colleges and universities, to a large extent, become the last training places before they enter the society and this four-year, has become an opportunity for them to gain valuable practical experience. 
Based on this situation, this study made a survey of the student cadres' leadership style, to explore possible characteristics of the students in the future work. On one hand, though there are many studies on leadership style, researchers mainly focus on enterprise management, especially on serving staff's leadership style. However, whether in China or abroad, research for college student cadres' leadership style is hardly to see. So this study makes an in-depth investigation in college student organizations, and hopes to provide reference for future research in this area. On the other hand, unlike experienced managers, the student cadres still lack practical experience in leadership, and the experience they gained in the student organization will affect their future work. Therefore, the reveal of college student cadres' leadership style will promote the study of enterprise or other organization management activities. Also, by comparing with executives' leadership style in reality, we hope this study can be a reference for higher education [1].

To be specific, the study content includes the following three aspects: 1) the main types of leadership styles and the proportion of each type; 2) the relationships between the types of leadership style and gender, organizational performance, and the department function; 3) based on the results of the study, it analyses the most suitable leadership style in college student organizations and tries to put forward the relevant suggestions of higher education talents training mode.

\section{Literature Review}

\subsection{Student Organizations and Student Cadres}

In China, student organizations must be in accordance with China's laws and regulations and set up according to the actual needs of the educational management. Student organizations are spontaneous composed of students based on their interests, hobbies, professional expertise and have some certain organization management function [2]. The main student organizations in Chinese college are the Youth League Committee, student union and student association.

The student organization is provided with a plurality of functional departments. Every department has its own affairs and responsibilities and equipped with 3 to 10 student cadres according to size of department. During the management work in these organizations, student cadres gradually formed their own unique style of leadership.

\subsection{Leadership Style}

To define the leadership style, we must distinguish between leader and leadership. Leader is someone who has powers and can influence others. And leadership is how the leaders do, in other words, is a process of influencing a group to achieve the target. In our life, some leaders to be courteous, amiable and easy of approach; some arbitrary and harsh; some democratic, these are different style of leadership [3].

Leadership style is a manner of using powers, or is a way that leaders used to influence others. It will have a far-reaching impact on an organization and its members and the research on leadership style has never stopped. By analyzing the behavior of the leaders, we can understand how leadership style influences the organizational members and find out the most suitable style of leadership [4].

\subsection{Contingency Theory}

There are lots of researches on leadership theory and some theories have been used in practice. Though various theories have different way of expression and focus according to different periods, they still in the same theoretical system. The main theory is shown in Table 1.

Contingency theory suggests that in a different context, different leadership behaviors have different effects and the basic leadership style of leaders is the key factors that affect success. In order to succeed, we need to study the phenomenon of leadership [5]. Contingency theory defines two dimensions of leadership: task behavior and relationship behavior. Based on these two dimensions, scholars have developed a number of models, including Fiedler's contingency model, Hersey and Blanchard's situational leadership model, leader participation model and path-goal model. Although these models have difference in classifying the specific types of leadership behavior, they are still consistent in classifying the leadership style. In this study, we designed the questionnaire and interview outline based on path-goal model and tried to interpret and analyze the results of our survey. On the one hand, path-goal model is more comprehensive and feasible than other models. On the other hand, because of the understandability, path-goal model is more accepted by the people in studying leadership style [6].

Path-goal model is a leadership theory developed by Robert House. The theory argues that leaders will have 
Table 1. Development of leadership theory.

\begin{tabular}{lcc}
\hline \multicolumn{1}{c}{ Period } & Leadership theory & Theme of research \\
\hline $\begin{array}{l}\text { 1940s to } 1950 \mathrm{~s} \\
\text { 1940s to 1960s }\end{array}$ & Trait theory & Focuses on the character trait \\
1960s to $1980 \mathrm{~s}$ & Contingency theory & Focuses on behavior style of leaders \\
Since the 1980s & New theory & Emphasizing the leader's vision and mission as well as the influence on members
\end{tabular}

Bryman, A. Charisma and Leadership in organizations [M]. London: SAGE Publication, 1992.

to engage in different types of leadership behavior depending on the nature and the demands of a particular situation. It is the leader's job to assist followers in attaining goals and to provide the direction and support needed to ensure that their goals are compatible with the organization's goals. The path-goal theory identifies achievement-oriented, directive, participative, and supportive leader behaviors:

The directive leader behavior refers to situations where the leader lets followers know what is expected of them and tells them how to perform their tasks.

The achievement-oriented leader behavior refers to situations where the leader sets challenging goals for followers, expects them to perform at their highest level, and shows confidence in their ability to meet this expectation.

The participative leader behavior involves leaders consulting with followers and asking for their suggestions before making a decision.

The supportive leader behavior is directed towards the satisfaction of subordinates needs and preferences. The leader shows concern for the followers’ psychological wellbeing.

\section{Methodology}

The object of this research is the college student cadres which come from the Youth League Committee, student union and some student associations in Loudi City, Hunan Province.

The research methods include literature review, questionnaire survey and interviews. The main source of the study mainly comes from Chinese science and technology journal data, Superstar Digital Library, and China National Knowledge Infrastructure (CNKI). Then we designed the leadership style questionnaire based on the Path-Goal Theory and survey the major leadership style of the student cadres. The leadership style questionnaire mainly includes two parts. The first part is samples of materials, including gender, grade, department and position. The second part is leadership style questionnaire. According to the path-goal model, we design 20 questionnaire items and survey the degree of using the four types of leadership style. The questionnaire is designed by Likert five-point scales. Item ranges from "strongly disagree” to "strongly agree”. "1" represents strongly disagree, “2” represents disagree, “3” represents not sure, “4” represents agree, “5” represents strongly agree. Finally, we interviewed with student leaders and collect some related recordings, to ensure a comprehensive study on the style of leadership. The first part of interview outline is personal information, including age, grade, department, position, etc. The second part is questions about student cadres' leadership style, including the following questions: What do you think about your leadership style? What's your reason for using a leadership style? Do you think the leadership style will affect the department performance and why? What's your view about the most suitable leadership style for student cadres? Due to limited space, we did not list detailed interview information [7].

\section{Research Results}

\subsection{Results of Questionnaire Survey}

In this study, we selected six colleges randomly and send 100 questionnaires to the student cadres, received 98 questionnaires, of which 93 valid questionnaires. The statistical results are as follows:

The main types of leadership styles and the proportion of each type are shown in Table 2 and Figure 1 . The type of complex means that the primary leadership style is more than one (shown in Table 3).

After subsuming the complex type into the four basic types, the main types of student cadres' leadership style are shown in Table 4 and Figure 2. 


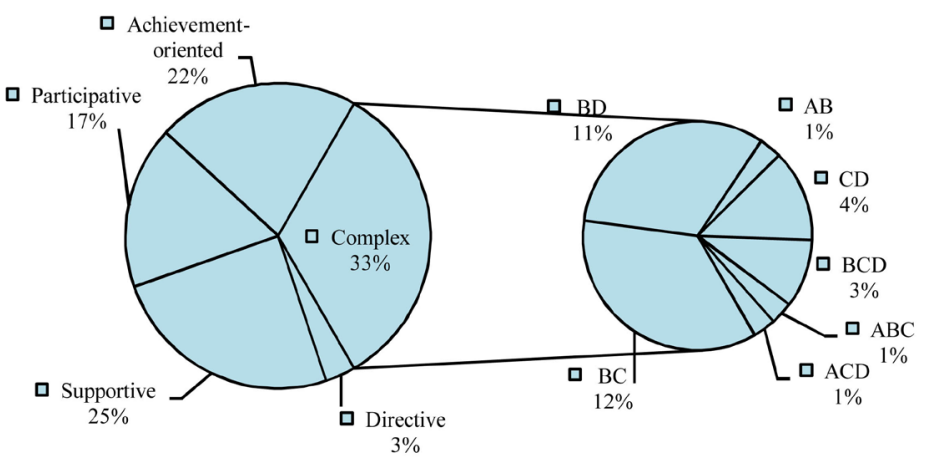

Figure 1. The main types of student cadres’ leadership style.

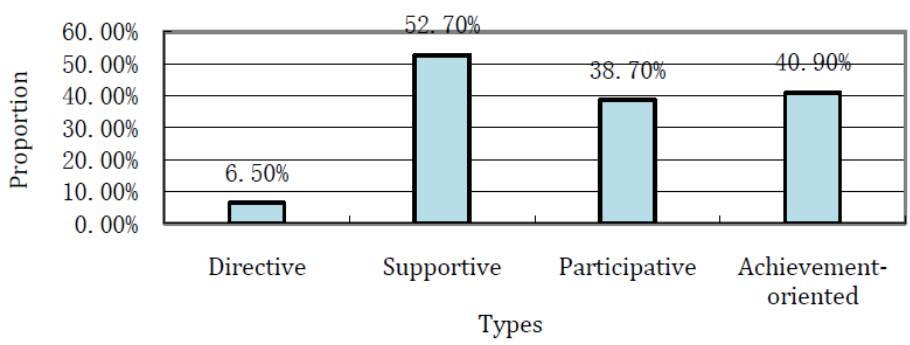

Figure 2. The main types of student cadres’ leadership style (repeat statistics).

Table 2. The main types of student cadres' leadership style.

\begin{tabular}{|c|c|c|c|c|c|}
\hline Types & Directive & Supportive & Participative & Achievement-oriented & Complex \\
\hline Number & 3 & 23 & 16 & 20 & 31 \\
\hline Percentage & $3.2 \%$ & $24.8 \%$ & $17.2 \%$ & $21.5 \%$ & $33.3 \%$ \\
\hline
\end{tabular}

Table 3. Complex type of leadership style.

\begin{tabular}{cccccccc}
\hline Complex & BC & BD & AB & CD & BCD & ABC & ACD \\
\hline Number & 11 & 10 & 1 & 4 & 3 & 1 & 1 \\
Percentage & $11.7 \%$ & $10.8 \%$ & $1 \%$ & $4.3 \%$ & $3.2 \%$ & $1 \%$ & $1 \%$ \\
\hline
\end{tabular}

Note: $\mathrm{A}$ = directive, $\mathrm{B}=$ supportive, $\mathrm{C}$ = supportive, $\mathrm{D}=$ achievement-oriented.

Table 4. The main types of student cadres’ leadership style (repeat statistics).

\begin{tabular}{ccccc}
\hline Types & Directive & Supportive & Participative & Achievement-oriented \\
\hline Proportion & $6.5 \%$ & $52.7 \%$ & $38.7 \%$ & $40.9 \%$ \\
\hline
\end{tabular}

From the chart, we can see that the main leadership style of student cadres are focus on supportive, participative and achievement-oriented types, whereas directive type is far less than the other three types, only 6.5\%. The largest number of type is supportive type, which reaching $52.7 \%$. And the proportion of single type and complex type is roughly $2: 1$.

In this study, the number of male was 36 and female was 57. The relationships between types of leadership style and gender are shown in Table 5 and Figure 3.

As can be seen from the chart, there was no significant difference in the gender dimension of student cadres' leadership style. The distribution of types in gender dimension is consistent with the entire distribution of student cadres’ leadership style.

In student organizations, though various departments have different functions, in order to facilitate our research, we divided these departments to supervision departments and non-supervision departments. Supervision departments are mainly engaged in supervision and assessment, while non-supervision departments are responsible for planning and statistics. From this perspective, there are 40 cadres come from supervision departments 
and 53 from non-supervision departments. The relationships between types of leadership style and department function are shown in Table 6 and Figure 4.

In the supervision departments, the proportions of supportive, participative and achievement-oriented types are close to $50 \%$, much larger than directive type. However, the proportion of supportive type in the non-supervision departments is larger than the other three types. Furthermore, supervision departments used more participative and achievement-oriented styles than the non-supervision departments.

In order to study the relationship between leadership styles and organizational performance, we collected the evaluation results of all the colleges and divided the top $27 \%$ colleges into high score group, the bottom $27 \%$ into low score group. Then we found that, in the sample of six colleges we selected, there are two colleges divided into high score groups and two into the low score group. The relationships between leadership styles and organizational performance are shown in Table 7 and Figure 5.

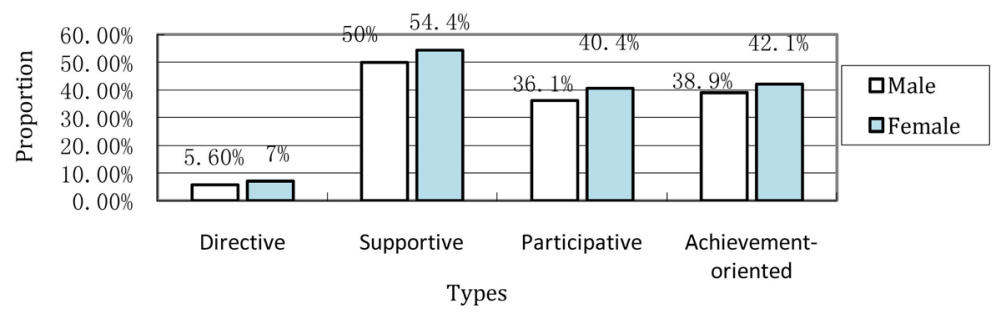

Figure 3. The main leadership style of female and male.

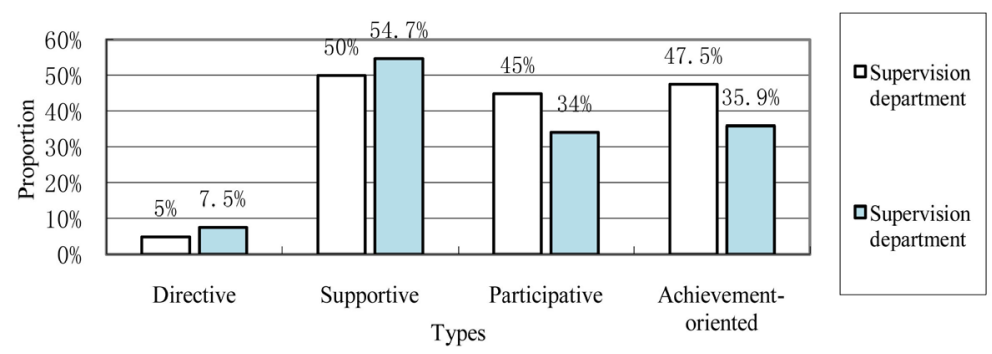

Figure 4. The main leadership style of supervision and non-supervision departments.

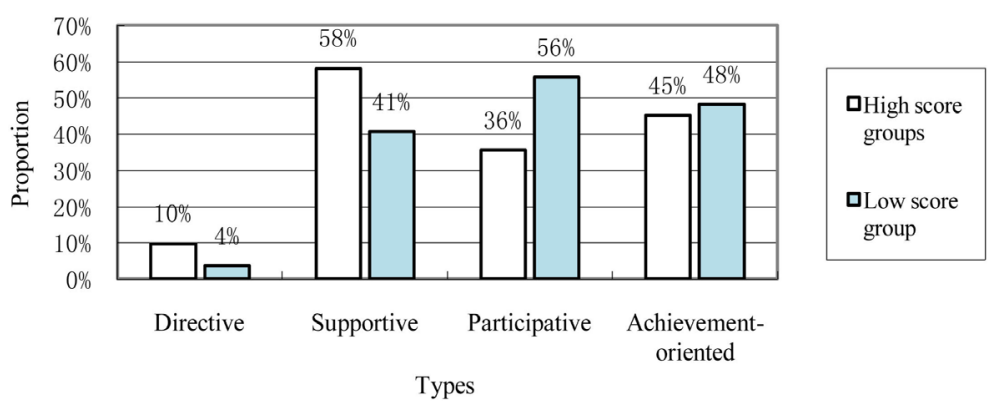

Figure 5. The main leadership style of high score groups and low score group.

Table 5. The main leadership style of female and male.

\begin{tabular}{cccccc}
\hline & Types & Directive & Supportive & Participative & Achievement-oriented \\
\hline \multirow{2}{*}{ Male } & Number & 2 & 18 & 13 & 14 \\
& Proportion & $5.6 \%$ & $50 \%$ & $36.1 \%$ & $38.9 \%$ \\
\multirow{2}{*}{ Female } & Number & 4 & 31 & 23 & 24 \\
& Proportion & $7 \%$ & $54.4 \%$ & $40.4 \%$ & $42.1 \%$ \\
\hline
\end{tabular}


Table 6. The main leadership style of supervision and non-supervision departments.

\begin{tabular}{cccccc}
\hline Types & & Directive & Supportive & Participative & Achievement-oriented \\
\hline $\begin{array}{c}\text { Supervision } \\
\text { department }\end{array}$ & Number & 2 & 20 & 18 & 19 \\
Proportion & $5 \%$ & $50 \%$ & $45 \%$ & $47.5 \%$ \\
Non-supervision & Number & 4 & 29 & 18 & 19 \\
\hline
\end{tabular}

Table 7. The main leadership style of high score groups and low score group.

\begin{tabular}{|c|c|c|c|c|c|}
\hline \multicolumn{2}{|c|}{ Types } & Directive & Supportive & Participative & Achievement-oriented \\
\hline \multirow{2}{*}{$\begin{array}{l}\text { High score } \\
\text { groups }\end{array}$} & Number & 3 & 18 & 11 & 14 \\
\hline & Proportion & $9.7 \%$ & $58.1 \%$ & $35.5 \%$ & $45.2 \%$ \\
\hline \multirow{2}{*}{$\begin{array}{l}\text { Low score } \\
\text { group }\end{array}$} & Number & 1 & 11 & 15 & 13 \\
\hline & Proportion & $3.7 \%$ & $40.7 \%$ & $55.6 \%$ & $48.1 \%$ \\
\hline
\end{tabular}

As we see from the chart, the proportion of supportive type in the high group has reached 58\%, much higher than the other three types. In the low score group, the highest proportion of type is participative style, reached $56 \%$. Therefore, the biggest difference of leadership style between high score group and low score group is the main leadership style. High score group uses more supportive leadership style, while the low score group is more frequent in using participative leadership style.

\subsection{Results of Interviews}

In order to better understand the leadership style of student cadres, we interviewed some student cadres and collected sound recordings. Lee is the chairman of student union, has three years of student work experience. "I am belongs to complex type, but more inclined to supportive type, this may be affected by the previous leader which always help me," says Lee. "Cares about your subordinates, can makes the organization more united." Similar to Lee, Wong, the president of a literary society, said that supportive style is the most suitable type in the work of student organization. "The reason is easy to see, we get together because of the same hobbies," says Wong. "If you always help others, they will turn to support you."

When it comes to performance and department function, most of student leaders think leadership styles indeed have an important impact on the work. Zhang is a minister of supervision department in Youth League Committee. She believes that doing assessment work needs a strict style in the supervision departments, so that can let others feel a sense of Justice. "However, single style is not enough to finish the job," says Zhang, "when I go for assessment task, I become achievement-oriented, but when I get along with my colleagues, I hope I am supportive enough."

Interestingly, when asked if there was a most suitable style to complete a variety of student work, they all agreed that it depends on the nature of the work. "You have to use different leadership styles in a changing environment," they said. What's more, they believe that the style of leadership which formed in these student organizations will be reflected in the future work.

\section{Discussion}

From the above research results we can draw some basic conclusions: 1) the main leadership styles of college student cadres are the type of supportive, participative and achievement-oriented, supportive type has the largest number and directive type has minimum; 2) male and female students had no significant difference on leadership style; 3 ) supervision departments used more participative and achievement-oriented style while non-supervision departments mainly used the supportive style; 4) high support style organizations do better on work than the low ones.

The research of college student cadres' leadership style actually is a study of how student cadres manage their organization and members, this process is the human resource management. Therefore, we can use some management and psychology theories to analyze our results. Maslow's hierarchy of needs theory suggests that the most basic level of needs must be met before the individual will strongly desire the secondary or higher level 
needs. He used the terms "physiological”, "safety”, "belongingness” and "love”, “esteem”, "self-actualization” and "self-transcendence" to describe the pattern that human motivations generally move through [8]. For college students, the physiological and safety needs have been met and the higher level of need is not easy to satisfy. Therefore, belongingness and love needs become the most strong pursue and this can explain why the supportive leadership style is so popular. Vroom's expectancy theory emphasizes the needs for organizations to relate rewards directly to performance and to ensure that the rewards provided are those rewards deserved and wanted by the recipients [9]. So when the students' need to be met, it will inspire them to make better performance, this can explain why the performance in high support organization is better than the low one.

Though this study has tried to follow the scientific principles throughout the research process, it still has some limitations. First, the demographic information of the 93 student cadres, such as age, length of student work experience, job title in student organizations, etc. is not provided in the survey. Hence, the result of research is not easy to generalize to other places. If possible, future research should take these factors into consideration. Second, we defaulted that the evaluation results of colleges is follow a normal distribution, so we use $27 \%$ as the standard to distinguish the high and low score groups, however, this may require further validation. Moreover, the evaluation of the colleges does not necessarily indicate the organizational performance, which is another limitation of the survey and future research may find more suitable evaluation methods to improve it.

\section{Conclusion}

In this study, we analyses the types of Chinese college student cadres' leadership style and the types' connection with gender, organization functions and performance from a view of contingency theory. At the same time, the study explores the most suitable style for the college student organization and at least provides three recommendations to higher education's talent cultivation: 1) Pay attention to the incentive mechanism of student organization and the high-level needs of student. 2) Focus on the training for student leaders to improve their theoretical knowledge and practical ability through lectures, seminars or intern practice. 3) Increase the types of student organization, improve the quality of student activities and provide more competitive and realistic platforms for student leaders to enhance their practical abilities.

\section{References}

[1] Qin, H., Han, Q. and Meng, H. (2011) The Effect of Leadership Style on Organizational Commitment in College Student Union. Psychological Research, 4, 46-51.

[2] Chen, Y. (2010) Study in Organization Construction of Higher Vocational Colleges Students. Suzhou University Press, Suzhou.

[3] Cui, K.F. (2011) The Impact of Leadership Style on Entrepreneurial Performance: An Empirical Study with Organizational Learning as the Mediator. Zhejiang University Press, Zhejiang.

[4] Stuke, K.B. (2013) Understanding Leadership through Leadership Understandings. Journal of Leadership Studies, 7, 55-61. http://dx.doi.org/10.1002/jls.21291

[5] Donaldson, L. (2001) The Contingency Theory of Organizations. Sage Publications, Inc., New York. http://dx.doi.org/10.4135/9781452229249

[6] Rui, M.J. (2005) Management: A Modern Perspective. People’s Publishing House, Beijing.

[7] Huang, X.T. and Zhang, Z.Z. (2010) Psychology Research Methods. 2nd Edition, Higher Education Press, Beijing.

[8] Frame, D. (1996) Maslow’s Hierarchy of Needs Revisited. Interchange, 27, 13-22. http://dx.doi.org/10.1007/BF01807482

[9] Chou, S.Y. and Pearson, J.M. (2012) Organizational Citizenship Behaviour in IT Professionals: An Expectancy Theory Approach. Management Research Review, 35, 1170-1186. http://dx.doi.org/10.1108/01409171211281282 
Scientific Research Publishing (SCIRP) is one of the largest Open Access journal publishers. It is currently publishing more than 200 open access, online, peer-reviewed journals covering a wide range of academic disciplines. SCIRP serves the worldwide academic communities and contributes to the progress and application of science with its publication.

Other selected journals from SCIRP are listed as below. Submit your manuscript to us via either submit@scirp.org or Online Submission Portal.
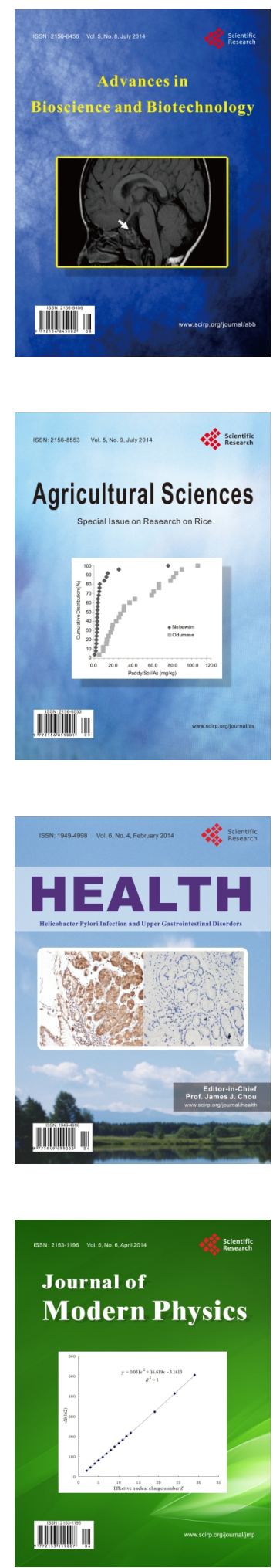
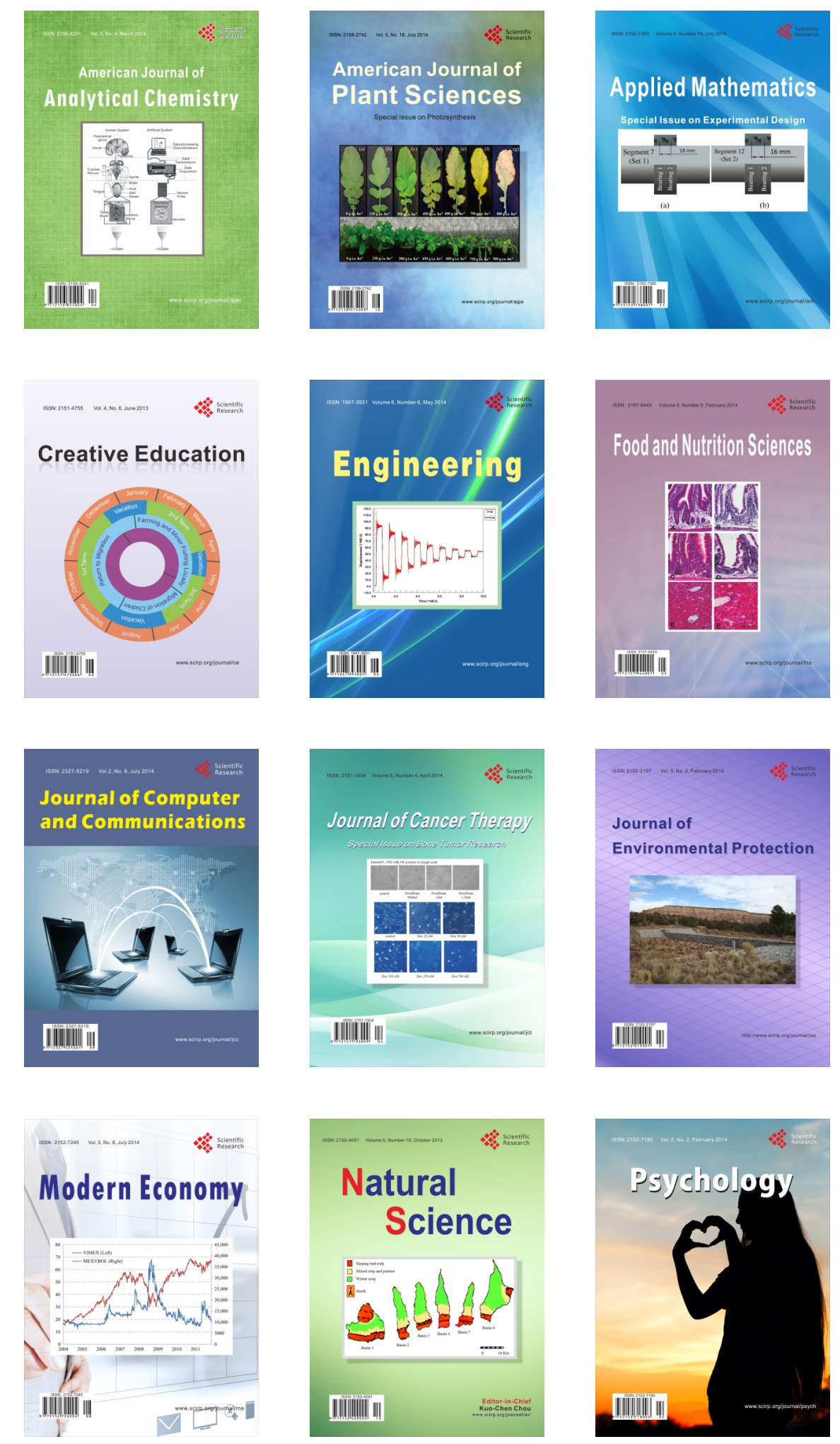